\title{
НАЛОГОПЛАТЕЛЬЩИКИ НАЛОГА НА ДОХОДЫ ФИЗИЧЕСКИХ ЛИЦ КАК ЗНАЧИМЫЕ УЧАСТНИКИ ИНИЦИАТИВНОГО БЮДЖЕТИРОВАНИЯ
}

\author{
Е.С. Вылкова, А.Д. Шматко*
}

В статье проанализировано состояние инициативного бюджетирования в мире и России и определены основные возможные направления его развития. Рассмотрены направления реформирования налогообложения доходов физических лиц в зарубежных странах и России за последнее время. Показана востребованность справедливо-действенного подхода к налогообложению. Обоснована целесообразность развития инициативного бюджетирования во взаимосвязи с реформированием налога на доходы физических лиц (НДФЛ) в части расширения прав почетных и заслуженных налогоплательщиков НДФЛ по участию в партисипаторном бюджетировании. Сформулированы предложения по внесению изменений в нормативно-правовую базу по вопросам инициативного бюджетирования, поощрению заслуженных и почетных налогоплательщиков и предоставлению им возможности активного участия в формировании перечня проектов и принятии решений об их финансировании.

Ключевые слова: налог, налогообложение, налог на доходы физических лиц, инициативное бюджетирование, справедливость, добросовестность

JEL-классификация: G38, H10, H21.

DOI: $10.46782 / 1818-4510-2020-2-143-152$

Материал поступил 29.04.2020 2.

Налоги в исторической ретроспективе всегда воспринимались налогоплательщиками как неизбежное зло, обременительная повинность, жертва для того чтобы государство выполняло свои функции. Людям хотелось также знать, на что конкретно тратится их личный рубль, внесенный в общественный фонд. Однако такая идентификация и сегодня, и ранее ни в действующем порядке формирования и расходования средств бюджетов, ни в налоговом законодательстве не предусматривается. Отсюда люди не видели оснований для любви к налогам и сомневались в справедливости налогообложения в своей стране и в мире.

Полагаем, что развитие инициативного бюджетирования во взаимосвязи с реформированием налога на доходы физических лиц в части расширения прав почетных и заслуженных налогоплательщиков НДФЛ по участию в партисипаторном бюд- жетировании способны изменить отношение граждан к оценке налогов и справедливости налогообложения, создать условия для повышения престижности добросовестного выполнения налоговых обязательств.

Рассматривая развитие инициативного бюджетирования в России и мире и законодательного регулирования НДФЛ в Российской Федерации, авторы вносят предложения по синхронной симметричной корректировке действующих правил в названных сферах в виде предоставления почетным и заслуженным налогоплательщикам НДФЛ специфических прав по участию в инициативном бюджетировании.

\section{Тенденции развития инициативного бюджетирования в России и мире}

В настоящее время в зарубежной и отечественной науке нет единообразия как в дефиниции общественного участия в це-

* Вылкова Елена Сергеевна (vylkova-es@ranepa.ru), доктор экономических наук, профессор, Северо-Западный институт управления Российской академии народного хозяйства и государственной службы (г. Санкт-Петербург, Россия);

Шматко Анна Дмитриевна (shmatko-ad@ranepa.ru), кандидат экономических наук, доцент, Северо-Западный институт управления Российской академии народного хозяйства и государственной службы (г. Санкт-Петербург, Россия). 
лом (Arnstein, 1969; Cogan, Sharpe, Hertzberg, 1986; Коваленко, Гришина, Рагозина, Пороховская, 2014), так и в подходах к идентификации общественного участия в бюджетном процессе (Ebdon, Franklin, 2006; Федосов, 2017). Формы общественного участия и их перечень регулируются в России положениями Бюджетного кодекса Российской Федерации, Федерального закона от 06.10.1999 г. № 184-ФЗ «Об общих принципах организации законодательных (представительных) и исполнительных органов государственной власти субъектов Российской Федерации», Федерального закона от 06.10.2003 г. № 131-Ф3 «Об общих принципах организации местного самоуправления в Российской Федерации», Федерального закона от 21 июля 2014 г. № 212-Ф3 «Об основах общественного контроля в Российской Федерации». Усиление гражданского общества и развитие информационных и телекоммуникационных технологий способствуют развитию быстрыми темпами общественного участия в бюджетном процессе.

К видам общественного участия в бюджетном процессе принято относить партисипаторное бюджетирование, зародившееся в 1989 г. в Бразилии, а в 2010 г. достигшее в мире по различным оценкам от 1269 до 2778 публично-правовых образований (Федосов, 2017. С. 115). Международная организация International Observatory on Participatory Democracy (IOPD) давно проводит престижный ежегодный конкурс проектов партисипаторного бюджетирования. Россия впервые приняла в нем участие в 2018 г., присоединившись к 65 странам-участницам, и сразу же Проект Республики Саха (Якутия) оказался среди 20 лучших практик, а затем вошел в пятерку лидеров инициативного бюджетирования. В СанктПетербурге при поддержке Всемирного банка и Министерства финансов Российской Федерации 18-19 апреля 2019 г. прошел международный форум «Общественное участие в развитии мегаполисов: расширение возможностей» (Public Participatory Forum) с участием международных экспертов из Бразилии, Исландии, Испании, Италии, Китая, Португалии, США и Южной Кореи.
Полагаем возможным согласиться с мнением В.А. Федосова (2017. С. 12), выделяющего в качестве одного из двух видов общественного участия граждан в бюджетном процессе активное участие в форме инициативного (партисипаторного) бюджетирования, когда гражданин инициативно принимает непосредственное участие либо голосованием по вопросам распределения бюджетных средств (общественные слушания, краудсорсинг и др.), либо участвует своими средствами - краудфандинг и др. Согласно мнения Научно-исследовательского финансового института (НИФИ) Министерства финансов Российской Федерации «под практикой инициативного бюджетирования понимается совокупность действий по реализации механизма и процедур участия граждан в бюджетных решениях, определенная особым порядком и закрепленная в нормативно-правовой и методической документации субъекта Российской Федерации или муниципального образования» ${ }^{1}$.

В настоящее время в научной электронной библиотеке словосочетание «инициативное бюджетирование» содержится в названии, аннотации и ключевых словах более чем 250 книг и статей. К наиболее цитируемым следует отнести статьи руководителя центра инициативного бюджетирования НИФИ Министерства финансов РФ (Вагин, 2016; Вагин, Гаврилова, Шаповалова, 2015). В экономической литературе исследуется как зарубежный опыт (Гаврилова, 2015); так и отечественная практика его применения (Шульга, Сухова, 2016; Чулков, 2017).

В России инициативное бюджетирование активно развивается. Оно в качестве одного из направлений входит в состав проекта Минфина РФ «Бюджет для граждан» и государственной программы «Управление государственными финансами и регулирование финансовых рынков». В названной программе содержится показатель по оценке развития инициативного бюджетирования - «число субъектов РФ, включивших в состав законодательных документов программы (мероприятия) о реализации на своей территории инициативного бюджетирования». Запланировано, что к 2024 г. количе-

${ }^{1}$ URL: https://www.minfin.ru/common/upload/library/ 2019/10/main/1070_Doklad.pdf 
ство таких субъектов составит не менее 62, при этом 33 субъекта РФ на конец 2018 г. уже имели названные программы (мероприятия). Разнообразие целей и задач, которые решаются различными государственными программами субъектов РФ с помощью инициативного бюджетирования, позволяет говорить о его самостоятельном и универсальном характере.

С 2018 г. Правительственная комиссия по координации деятельности открытого правительства утвердила Программу развития инициативного бюджетирования в Российской Федерации. В Основных направлениях деятельности Правительства Российской Федерации на период до 2024 года содержится такое мероприятие как: «внедрение и обучение механизмам участия граждан Российской Федерации в решении вопросов социально-экономического развития соответствующих территорий на основе широко распространенной в мире концепции партисипаторного (инициативного) бюджетирования». В Концепции повышения эффективности бюджетных расходов в 2019-2024 гг. ${ }^{2}$ сформулировано как будет развиваться инициативное бюджетирование в среднесрочной перспективе.

В России проекты инициативного бюджетирования с 2013 г. обсуждаются на федеральном уровне, а с 2016 г. стали реализовываться на региональном уровне. Такая практика впервые была запущена в СанктПетербурге. Следует отметить, что уже в начале 2000-х годов у Всемирного банка был накоплен большой опыт реализации инициативных программ в бюджетном процессе, в частности программ Communitybased development. В 2006 г. Правительство РФ начало обсуждение со Всемирным банком возможностей разработки и реализации в России подобных программ. В результате в 2007 г. в муниципальных образованиях Ставропольского края РФ стартовала «Программа поддержки местных инициатив». Всего в муниципальных образованиях РФ с 2007 по 2015 г. было реализовано около 3000 проектов названной Программы (Шульга, 2016). 72064730
Центр инициативного бюджетирования НИФИ Минфина России ежегодно выпускает доклады с информацией о лучших практиках развития инициативного бюджетирования в субъектах Российской Федерации и муниципальных образованиях, данные последнего из которых используются авторами в дальнейшем изложении вопросов инициативного бюджетирования ${ }^{3}$.

В 2018 г., согласно данным НИФИ Минфина России, в 68 субъектах Федерации было 193 различных практик участия граждан в определении приоритетных направлений расходования бюджетных средств, по сравнению с тем, что в 2017 г. было только 112 практик, а в 2015 г. - 31 практика.

В 2018 г. направлено на проекты 19,3 млрд руб., что на 5 млрд руб. больше показателя предыдущего года. Объем бюджетных средств по финансированию из бюджетов субъектов РФ составил 10,5 млрд руб., на 2,5 млрд руб. больше чем в предыдущем году. Среди реализуемых проектов наибольшая доля финансирования из бюджета субъекта составляет в Республике Башкортостан: по 5 практикам из 1593,3 млн руб. бюджетное финансирование было 1228,1 млн руб.

В 2018 г. было реализовано 18725 проектов инициативного бюджетирования (всего гражданами было предложено более 88 000 идей, из них более 23000 были признаны соответствующими условиям и допущены к участию в конкурсных процедуpax), что почти на 3 тыс. больше показателей 2017 г., большинство из которых были следующих типов (перечисленные ниже категории являлись приоритетными и в предыдущие годы):

автомобильные дороги, тротуары, пешеходные переходы, остановки (15,1\%);

места массового отдыха граждан и объекты благоустройства территорий $(9,4 \%)$; водоснабжение, водоотведение $(8,5 \%)$; уличное освещение $(8,4 \%)$.

Проекты комплексного благоустройства дворов (8,4\%) - данная категория появилась с 2018 г., наряду с проектами в

${ }^{3}$ URL: https://www.minfin.ru/common/upload/library/ 2019/10/main/1070_Doklad.pdf 
сфере образования, культуры, по поддержке лиц с ограниченными возможностями и другими.

В 2018 г. проект имел стоимость в среднем 1,0 млн руб., из которых 0,6 млн руб. составляли бюджетные средства, что выше по сравнению с показателями 2017 г. - 0,9 млн и 0,5 млн руб. соответственно. При этом в реализованных проектах в 68 регионах РФ доля благополучателей составила около $23,3 \%$ от общего числа граждан, проживающих в данных субъектах РФ. Наивысшая доля благополучателей проектов инициативного финансирования зафиксирована в Нижегородской области - $69,02 \%$ от общей численности населения; второе место принадлежит Ставропольскому краю - 76,48\%.

В инициативном бюджетировании есть возможность участия широкого круга граждан как при выдвижении идей, так и при обсуждении и выборе проектов через различные очные и заочные механизмы, различающиеся в зависимости от конкретного региона. Например, в Сахалинской области при реализации проекта «Развитие территорий» на местном уровне (в населенных пунктах с численностью более 100 чел.) участники собраний граждан на основе прямого голосования выбирают 3 делегатов для последующего представления населенного пункта и отобранного собранием проектного предложения. На происходящих затем встречах делегатов формируется муниципальный рейтинг проектных предложений, из которого два предложения с наибольшим количеством голосов выносятся на итоговое голосование. В ходе общеобластного голосования граждан выбираются проекты-победители. В Череповце, где одним из самых первых в РФ с 2013 г. стали реализовывать проект «Народный бюджет», бюджетная комиссия формируется путем жеребьевки из числа жителей, заявивших о готовности участвовать в проекте. Комиссии делегируется предложение инициатив и распределение на них бюджетных средств. При этом в Череповце есть интеграция инициативного бюджетирования и механизма территориального общественного самоуправления. Таким образом, назначение части средств городского бюджета определяют сами горожане в ходе «народного голосования», а рабочая группа их утверждает.
Вопросы участия граждан в инициативном финансировании рассматриваются в публикациях с начала 2000-х годов (Грембергер, 2002) по настоящее время (Коростелева 2019; Помазанский, 2019).

В целях дальнейшего развития инициативного финансирования в среднесрочной перспективе целесообразно использование форм общественного участия, демонстрирующих наилучшие результаты; активизация просветительской работы с гражданами по более широкому их включению в бюджетный процесс и повышению уровня финансовой грамотности; рост числа и доступности дискуссионных площадок по проблемам и инициативам населения и экономических субъектов.

Перечисленные мероприятия направлены на активизацию вовлечения граждан и корпораций в бюджетный процесс, повышение его прозрачности и открытости, что особенно актуально в условиях чрезвычайной ситуации, сложившейся в мире в условиях пандемии COVID-19, в целях повышения эффективности расходования бюджетных средств.

Общественное участие в бюджетном процессе сегодня как никогда важно осуществлять на принципах открытости (прозрачности) (Вершило, 2018). Органы власти должны понимать, что только при наличии в обществе открытости и доверия они способны поднять бюджетные отношения на новый качественный уровень; способствовать успешному решению задач стабильного социально-экономического развития, повышению общественного благосостояния.

По уровню открытости бюджета РФ не только занимает одно из первых мест в мире, но и с 2014 г. продолжает существенно улучшать этот показатель, когда на федеральном уровне стали формировать программный бюджет. Однако еще многое предстоит сделать по ряду направлений совершенствования общественного участия в бюджетном процессе. Ряд исследователей справедливо указывают на сложность определения фактического уровня участия граждан в бюджетном процессе (Федосов, 2017). Следует отметить, что это участие связано с вопросами налогообложения, которым до последнего времени не уделялось 
должного внимания в исследованиях российских практиков и ученых.

Как мы видим, варианты принятия решений по выбору проектов инициативного бюджетирования и их финансированию могут быть различными. При этом возникает вопрос: насколько справедливы, обоснованы и мудры эти решения? Авторы не претендуют на разработку единственно верного решения названной проблемы. Тем не менее, для повышения обоснованности выбора объектов инициативного бюджетирования и уровня справедливости расходования на них бюджетных средств считаем возможным предложить вовлечение более широкого участия в названных процессах граждан - плательщиков НДФЛ в наиболее крупном размере.

\section{Совериенствование законодательного регулирования НДФЛ в Российской Федерации}

Порядок налогообложения доходов физических лиц различается по странам и перманентно реформируется в них. В экономической литературе есть большое количество публикаций, посвященных различным аспектам подоходного налога. Н.Г. Викторова и Л.К. Аитова (2016) анализируют его в странах БРИКС; Н.В. Покровская (2017) акцентирует внимание на его важности для доходов местных бюджетов. В монографии Е.С Вылковой и А.Л. Тарасевича (2010) обобщена информация о налогообложении труда в 110 странах. Названные авторы также исследовали тенденции развития налогообложения доходов физических лиц в РФ и странах ОЭСР (Вылкова, Тарасевич, 2018).

В России НДФЛ регулируется положениями 23 главы Налогового кодекса Российской Федерации, в которую постоянно вносятся изменения. Прежде всего, следует указать, что в условиях нормальной, а не кризисной экономики реформирование НДФЛ происходит перманентно с учетом национальных особенностей. Данные, размещенные на сайте ОЭСР ${ }^{4}$, позволяют сформулировать основные тенденции новаций в этой сфере за последнее время.

\footnotetext{
${ }^{4}$ URL: https://doi.org/10.1787/da56c295-en
}

Ряд стран, такие как Ирландия, Норвегия, Португалия Финляндия, снижали в последнее время ставки по НДФЛ для граждан, относящихся к малообеспеченным и социально незащищенным слоям населения. Канада, Люксембург и Словения снизили налоговые ставки для работников, имеющих средний уровень доходов. В ряде стран произошло уменьшение налоговой базы для вышеназванных слоев населения.

Аргентина, Бельгия, Великобритания, Германия, Ирландия, Латвия, Люксембург, Нидерланды, Норвегия, Словения, Финляндия, Эстония осуществили нововведения по поддержке налогоплательщиков в части личных пособий и налоговых кредитов по НДФЛ.

В Ирландии, Люксембурге, Польше и Финляндии произошло увеличение сумм необлагаемого дохода.

В Австралии, Германии, Венгрии, Люксембурге, Чехии и Ирландии законодательно изменили в пользу налогоплательщиков размер вычетов на детей, в Нидерландах больше стала поддержка пожилых людей и инвалидов.

Многие страны, такие как Бельгия, Венгрия, Исландия, Люксембург, Португалия, Словакия, Финляндия, Швеция и Эстония приняли меры по повышению деловой активности граждан на основе стимулирования различных инвестиций, инноваций и предпринимательства, а также привлечения высококвалифицированных работников путем предоставления различных преференций по НДФЛ.

Перечисленные выше инструменты представляют интерес для их использования в реформировании НДФЛ в Российской Федерации в условиях стабильности.

Однако, полагаем, что в настоящее время реформирование НДФЛ в России должно происходить, прежде всего, в направлении поддержки населения в условиях пандемии с учетом имеющихся наработок в этом вопросе в зарубежных странах.

Форум по налоговому администрированию (FTA) на основе сведений, представляемых налоговыми администрациями соответствующих государств, собирает информацию по различным финансовым и налоговым мерам реагирования на чрезвычай- 
ную ситуацию COVID-19 по 106 государствам $^{5}$.

По состоянию на 10 апреля 2020 г. изменения в налогообложении доходов физических лиц (РIT) внесены в 49 странах. Наибольшее количество изменений произведено в США - 10 мер. Среди мер, введенных в США еще 27 марта 2020 г. следует назвать: изменение правил учета убытков и банкротства; увеличение размера вычетов по благотворительным взносам и плате за обучение и другие. В Австрии и Египте принято по 5 мер. В Австрии предусмотрено снижение вдвое ставки НДФЛ для вышедших на пенсию врачей, возвращающихся с пенсии в связи с кризисом Covid-19; сделанные в 2020 г. бонусные платежи работникам в размере 3000 евро не облагаются налогом; предприятиям предоставлена возможность сократить авансовые платежи НДФЛ в течение 2020 г. вплоть до нуля без начисления штрафных санкций. Египет установил снижение налога на дивиденды с 10 до 5\%; освобождение от налогообложения прироста капитала по ценным бумагам, включенным в египетские акции. В Узбекистане приняты 3 меры. В остальных государствах - по 2 или 1 мере. При этом большинство мер предусматривают снижение ставок по тем или иным видам доходов.

Перечисленные выше меры по поддержке населения в условиях пандемии коронавирусной инфекции путем ослабления налогового бремени по налогообложению труда являются актуальными для России и требуют скорейшего их введения. Значение преференций для решения задач социально-экономического развития конкретного государства и его территорий трудно переоценить (Вылкова, Красавин, 2011). Данные меры позволят гражданам страны осознать, что государство о них заботится и не имеет намерений свалить на их плечи всю

5 URL: https://read.oecd-ilibrary.org/view/?ref= 128_128290-cy6mbvet5x\&title=Tax-administration-responses-tocovid-19-business-continuity-consideration; URL: https:// read.oecd-ilibrary.org/view/?ref=126_126478-29c4rprb3y\& title=Tax_administration_responses_to_COVID-9_Measures_ taken_to_support_taxpayers; URL: https://www.oecd.org/ coronavirus/en/; URLLhttps://www.oecd.org/tax/administration/ tackling-the-coronavirus-oecd-forum-on-tax-administrationpublishes-actions-that-fta-tax-administrations-are-currently-takingto-support-taxpayers.htm тяжесть как в период пандемии, так и на выходе из кризиса.

Отметим, что в РФ в рамках мер по борьбе с последствиями COVID-19 1 апреля 2020 г. были внесены последние поправки по увеличению бремени НДФЛ в части обложения процентов по вкладам населения, превышающим 1 млн руб. Вызывает недоумение явная поспешность в принятии такого решения по увеличению налогового бремени на домохозяйства. Согласно положениям статьи 5 Налогового кодекса РФ, подобную правку не поздно было бы вносить вплоть до 1 декабря 2020 г. К тому же деньги от данного нововведения поступят в бюджет только в конце 2022 г., и вряд ли это можно расценивать как поиск средств для оперативного решения вопросов в чрезвычайных условиях пандемии. Подобную меру следует отнести к обеспечительным для успешного выхода из кризисной ситуации. На пике пандемии она, как показано выше, не имеет никакого значения в силу отложенного во времени поступления средств в соответствующие бюджеты. Вызывает сомнение, что именно за счет этого возможно и целесообразно строить стратегию успешного выхода из кризисной ситуации в соответствии с действенно-справедливым подходом к налогообложению доходов физических лиц (Вылкова, Тарасевич, 2017).

Налоги и их уплата должны строиться не только на основе справедливости, но в условиях обеспечения возрастания престижности налогоплательщиков, добросовестно исполняющих налоговые обязательности.

До настоящего момента в российской практике и в научных исследованиях анализировался лишь карательный аспект последствий недобросовестного поведения участников налоговых отношений. Настало время перейти в этом вопросе от кнута к прянику.

Поднять престижность уплаты НДФЛ позволят, в частности, меры по включению граждан, которые платят его в наибольшем размере на соответствующей территории в состав органов, которые в конкретном субъекте РФ или муниципальном образовании принимают решения по различным вопросам инициативного финансирования.

В России, согласно положениям Конституции и реалиям настоящего этапа ее 
развития, необходимо обеспечение максимальной справедливости общественных отношений, в том числе в сфере публичных финансов. На основе анализа смыслового наполнения термина «справедливость» с учетом его этимологии, лингвистики и исторического обзора развития идентификации данного понятия доказано, что его следует идентифицировать не столько как равенство, а как соразмерность ${ }^{6}$.

Решение каждого сложного вопроса, в конце концов, упирается в поиски авторитета. И такой авторитет должен быть безусловным. Люди нуждаются в серьезном арбитре, который бы мог рассудить и посоветовать варианты наиболее грамотных решений того или иного вопроса. Это касается и партисипаторного бюджетирования.

В Древней Греции, Древнем Риме, в Израиле, в период Директории во Франции, на Руси в X в., в каждой из палат Верховного Совета СССР и Верховных советов союзных и автономных республик, Государственной думе Российской империи вопросы управления государством решались с учетом мнения совета старейшин, называвшегося соответственно Ареопаг, Сенат, Синедрион и т. д. В настоящее время важную роль в жизни некоторых народов также играет совет старейшин: старейшины тейпов у чеченцев и при Президенте Дагестана; аксакалы у тюркских народов; в виде фракции он существует в Бундестаге Германии. В 2001 г. создан Совет старейшин при мэре Москвы. В последнее время активно обсуждается необходимость создания Совета старейшин при Президенте РФ. С 2017 г. в общественном режиме функционирует Совет старейших мудрецов России.

Смысловая нагрузка понятия старейшин обычно состоит в том, что это пожилые и уважаемые люди, умудренные опытом.

Полагаем, что люди, заплатившие на соответствующей территории наибольшую сумму подоходного налога, обладают двумя качествами старейшин:

имеют большой опыт трудовой и предпринимательской деятельности, позволивший им получить значимую сумму дохо-

${ }^{6}$ Вылкова Е.С. 2017. Методические подходы к оценке уровня справедливости налогового законодательства. Экономика. Налоги. Право. № 4. С. 6-13. дов, часть которой поступила в бюджет в виде НДФЛ;

заслуживают уважения, так как являются честными налогоплательщиками, получающими солидные «белые» доходы, подлежащие налогообложению, не уклоняются от уплаты НДФЛ, не уводят деньги в оффшорные юрисдикции.

То, что их возраст не всегда почтенный, не препятствует признанию их статусности как почетного или заслуженного налогоплательщика НДФЛ.

Таким налогоплательщикам может быть предложено (ни в коем образе не вменено в обязанность, пусть даже и почетную) принять участие в отборе лучших инициатив для получения финансирования в рамках партисипаторного бюджетирования с правом включения проектов, исходя из собственных представлений об их целесообразности.

Расставим правильно все акценты. Мы не утверждаем, что заслуженные налогоплательщики имеют право быть непререкаемыми судьями в вопросах инициативного бюджетирования. Речь идет лишь о том, что им можно доверить находиться в составе тех, кто принимает решение о выборе конкретных проектов партисипаторного бюджетирования и размере их финансирования, с ними можно посоветоваться по этим вопросам, их рекомендации следует считать значимыми. И чем больше доля его личного вклада в объем собранного на соответствующей территории НДФЛ, тем большего доверия заслуживает такой гражданин.

Степень заслуженности налогоплательщика НДФЛ можно определить различными способами.

Взять за основу сумму НДФЛ, уплаченную конкретным физическим лицом по доходам, облагаемым по ставке 13\% (доходы, облагаемые по другим ставкам, считаем невозможным включать в расчет в силу их недостаточно системного характера), за соответствующий налоговый период (календарный год). В зависимости от суммы возможно осуществлять ранжирование и составлять списки заслуженных и (или) почетных налогоплательщиков:

по РФ в целом, с вручением им почетных грамот от Правительства, Министерства Финансов или ФНС РФ (ТОП 500, 
по аналогии с тем, как Финансовый университет при Правительстве РФ составляет рейтинг ведущих экономистов РФ);

по субъекту РФ, с вручением им почетных грамот от Правительства, комитета Финансов или УФНС по соответствующему субъекту (ТОП 50);

по муниципальным округам (ТОП 5).

Соответствующие нормы следует прописать в специальном Постановлении Правительства РФ, по примеру в отношении почетных и заслуженных деятелей науки, искусства и т. д.

Кроме этого, возможно считать степень заслуженности на уровне региона и муниципалитета как долю НДФЛ, уплаченного конкретным физическим лицом по доходам, облагаемым по ставке 13\%, за соответствующий налоговый период, в доходах рассматриваемой территории. Назовем этот показатель долей личного вклада конкретного физического лица в формирование доходной базы соответствующего бюджета $\left(Д_{л}\right)$. Названный показатель можно, кроме того, корректировать, умножая его на долю доходов от НДФЛ в составе налоговых доходов (Д 56, 61.1, 61.2, 61.3 Бюджетного кодекса Российской Федерации НДФЛ, взимаемый на соответствующей территории, подлежит зачислению по следующим нормативам:

85\% в бюджеты субъектов РФ;

$5 \%$ городских поселений;

$13 \%$ сельских поселений;

15\% межселенных территорий;

$15 \%$ городских округов (в том числе с внутригородским делением).

Возможна корректировка также на долю средств бюджета в финансировании проектов инициативного финансирования (Д мер, в 2018 г. в Нижегородской области было реализовано проектов инициативного бюджетирования на сумму 608,0 млн рублей, в том числе: $50,0 \%$ - из регионального бюджета, $31,7 \%$ - из бюджетов муниципалитетов, $6,0 \%$ софинансирование физическими лицами, $12,2 \%$ - юридическими лицами ${ }^{7}$.

Используя приведенные показатели можно считать индекс значимости конкретного налогоплательщика НДФЛ $\left(И_{\text {зн }_{\mathrm{n}}}\right)$ :

${ }^{7}$ URL: https://www.minfin.ru/common/upload/library/ 2019/10/main/1070_Doklad.pdf

$$
И_{\text {зн н }}=Д_{Л} \cdot Д_{\text {ндФл }} \cdot Д_{б с} \cdot
$$

Исходя из уровня значимости конкретного налогоплательщика, ему может быть предложено принять активное участие в партисипаторном бюджетировании.

Президент и Правительство Российской Федерации во многих вопросах прислушиваются к мнению таких общественных организаций как Союз промышленников и предпринимателей России, Комитет гражданских инициатив и других. Союз налогоплательщиков вполне реально создать либо в рамках Союза промышленников РФ, либо в форме автономной организации.

При этом, вне зависимости от того, будет создана подобная общественная организация или нет, почетные и заслуженные налогоплательщики уже сегодня могут быть включены в систему инициативного бюджетирования. Для этого в законодательную базу, регулирующую вопросы партисипаторного бюджетирования, необходимо внести коррективы по предоставлению заслуженным налогоплательщикам возможности активного участия в формировании перечня проектов и принятии решений об их финансировании.

Комплексное рассмотрение вопросов оценки состояния инициативного бюджетирования и налогообложения доходов физических лиц и определение основных направлений их развития в среднесрочной перспективе показали востребованность справедливо-действенного подхода к налогообложению для обеспечения престижности налогоплательщиков, добросовестно исполняющих налоговые обязательства.

Целесообразно развитие инициативного бюджетирования во взаимосвязи с реформированием налога на доходы физических лиц в части расширения прав почетных и заслуженных налогоплательщиков НДФЛ по участию в партисипаторном бюджетировании. Для этого необходимо внесение изменений в нормативно-правовую базу по вопросам инициативного бюджетирования, поощрения заслуженных и почетных налогоплательщиков и предостав- 
ление им возможности активного участия в формировании перечня проектов партисипаторного бюджетирования и принятии решений об их финансировании.

Названные новации призваны способствовать повышению обоснованности выбора объектов инициативного бюджетирования, уровня справедливости расходования на них бюджетных средств и, в итоге, росту благосостояния нации и социальноэкономическому развитию экономики государства.

\section{СПИСОК ЛИТЕРАТУРЫ (REFERENCES)}

Вагин В.Г. (Ред.). 2016. Инициативное бюджетирование в Российской Федеращии: сборник научных материалов к II Всероссийской конференции по инициативному бюджетированию. Вып. 2. Москва: Научно-исследовательский финансовый институт. 112 с. [Vagin V.G. (Ed.). 2016. Proactive budgeting in the Russian Federation: collection of scientific materials for the II All-Russian conference on proactive budgeting. Iss. 2. Moscow: Nauchno-issledovatel'skiy finansovyy institut. 112 p. (In Russ.)]

Вагин В.В., Гаврилова Н.В., Шаповалова Н.А. 2015. Инициативное бюджетирование: международный контекст российской версии. Научно-исследовательский финансовый институт. Финансовый журнал. № 3. C. 117-122. [Vagin V., Shapovalova N., Gavrilova N. 2015. Initiative budgeting: International context of Russian version. Nauchno-issledovatel'skiy finansovyy institut. Finansovyy zhurnal. No 3. PP. 117-122. (In Russ.)]

Вершило Т.A. 2018. Прозрачность (открытость) бюджетных отношений в условиях цифровой экономики. Финансовое право. № 8. C. 8-11. [Vershilo T.A. 2018. Transparency (publicity) of budget relationships in the conditions of digital economy. Finansovoe parvo. No 8. PP. 8-11. (In Russ.)]

Викторова Н.Г., Аитова Л.К. 2016. Подоходный налог в странах БРИКС: аналитический аспект. Актуальные проблемы науки и практики. № 1. C. 22-26. [Viktorova N.G., Aitova L.K. 2016. Income tax in the BRICS countries: analytical aspect. Aktual'nye problemy nauki i praktiki. No 1. PP. 2226. (In Russ.)]

Вылкова Е.С., Красавин В.И. 2011. Формирование налоговых льгот в субъектах Российской Федерации (на примере СЗФО). Санкт-Петербург: Издательство Центра подготовки персонала Федеральной налоговой службы. 277 с. [Vylkova E.S., Krasavin V.I. 2011. Formation of tax benefits in the constituent entities of the Russian Federation (by the example of the NWFD). St. Petersburg: Izdatel'stvo
Tsentra podgotovki personala Federal'noy nalogovoy sluzhby. 277 p. (In Russ.)]

Вылкова Е.С., Тарасевич А.Л. 2010. Кониептуальные основы реформирования налога на доходы физических лии в России. Санкт-Петербург: Издательство СПбГЭУ. 211 с. [Vylkova E.S., Tarasevich A.L. 2010. Conceptual framework for reforming the tax on personal income in Russia monograph. St. Petersburg: Izdatel'stvo SPbGEU. 211 p. (In Russ.)]

Вылкова Е.С., Тарасевич А.Л. 2017. Совершенствование налогообложения доходов и имущества физических лиц в России на основе справедливо-действенного подхода. Проблемы современной экономики. № 3. С. 38-42. [Vylkova E.S., Tarasevich A.L. 2017. Improving taxation of profits and property of Russia's physical persons on the basis of justice-and-efficacy approach. Problemy sovremennoy ekonomiki. No 3. PP. 38-42. (In Russ.)]

Вылкова Е.С., Тарасевич А.Л. 2018. Совершенствование налогообложения труда в странах ОЭСР и Российской Федерации. Экономика. Налоги. Право. № 3. С. 121-130. [Vylkova E.S., Tarasevich A.L. 2018. Improving the Personal Taxation in OECD countries and the Russian Federation. Ekonomika. Nalogi. Pravo. No 3. PP. 121130. (In Russ.)]

Гаврилова Н.В. 2016. Зарубежные тренды в сфере партисипаторного бюджетирования. Научноисследовательский финансовый институт. Финансовый журнал. № 2. C. 118-125. [Gavrilova N.V. 2016. The Current Trends in Participatory Budgeting. Nauchno-issledovatel'skiy finansozyy institut. Finansozyy zhurnal. No 2. PP. 118-125. (In Russ.)]

Грембергер М. 2002. Граждане как партнеры. Руководство ОЭСР по информированию, консультациям и активному участию общества в разработке политического курса. Москва: Издательство «Весь Мир». 120 с. [Gremberger М. 2002. Citizens as partners. OECD handbook on information, consultation and public participation in policy-making. Moscow: Izdatel'stvo «Ves' Mir». 120 p. (In Russ.)]

Коваленко Е. А., Гришина Е.Е., Рагозина Л.Г., Пороховская М.А. 2014. Участие общественных коллегиальных органов управления в социальных услугах. Российский и зарубежный опыт. Москва: Издательский дом Дело. 234 с. [Kovalenko E.A., Grishina E.E., Ragozina L.G., Porokhovskaya M.A. 2014. Participation of community collegial governing bodies in social services. Russian and foreign experience. Moscow: Izdatel'skiy dom Delo. 234 p. (In Russ.)]

Коростелева М.В. 2019. Инициативное бюджетирование как форма участия населения в процессе принятия бюджетных решений на муниципальном уровне: особенности правового регулирования. Государственная власть и местное самоуправление. № 6. C. 46-49. [Korosteleva M.V. 2019. Proactive budgeting as a form of involvement of the population in the budget-related resolution 
adoption process on the municipal level: Legal regulation peculiarities. Gosudarstvennaya vlast' $i$ mestnoe samoupravlenie. No 6. PP. 46-49. (In Russ.)]

Покровская Н.В. 2017. Зачисление налога на доходы физических лиц в местные бюджеты в Российской Федерации. Экономика. Налоги. Право. № 3. C. 146-151. [Pokrovskaya N.V. 2017. The Payment of the Personal Income Tax to Local Budgets of the Russian Federation. Ekonomika. Nalogi. Pravo. No 3. PP. 146-151. (In Russ.)]

Помазанский А.E. 2019. Соотношение традиционных и новых форм участия граждан в осуществлении местного самоуправления. Журнал российского права. № 11. С. 58-68. [Pomazanskiy A.E. 2019.The ratio of traditional and new forms of citizen participation in the implementation of local self-government. Zhurnal rossiyskogo prava. No 11. PP. 58-68. (In Russ.)]

Федосов В.А. 2017. Общественное участие в бюджетном прочессе: зарубежный опыт и российская практика. Санкт-Петербург: Санкт-Петербургский государственный экономический университет. 143 с. [Fedosov V.A. 2017. Public participation in the budget process: foreign experience and Russian practice. Sankt-Peterburg: SanktPeterburgskiy gosudarstvennyy ekonomicheskiy universitet. 143 p. (In Russ.)]
Чулков А.C. 2017. Опыт и перспективы применения в России инициативного бюджетирования. Бухгалтерский учет в бюджетных и некоммерческих организащиях. № 11. C. 14-23. [Chulkov A.S. 2017. Experience and prospects for the application of initiative budgeting in Russia. Bukhgalterskii uchet $v$ byudzhetnykh $i$ nekommercheskikh organizatsiyakh. No 11. PP. 14-23. (In Russ.)]

Шульга И.Е., Сухова А.С. 2016. Программа поддержки местных инициатив: совершенствование местного самоуправления и развитие инициативного бюджетирования. Москва: «Алекс». 52 с. [Shulga I.E., Sukhova A.S. 2017. Program for supporting local initiatives: improving local government and developing proactive budgeting. Moscow: «Aleks». 52 p. (In Russ.)]

Arnstein S.R. 1969. A Ladder of Citizen Participation. Journal of the American Institute of Planners. Vol. 35. No 4. PP. 216-224.

Cogan A., Sharpe S., Hertzberg J. 1986. Citizen Participation. The Practice of State and Regional Planning. Chicago: American Planning Association.

Ebdon C., Franklin A.L. 2006. Citizen Participation in Budgeting Theory. Public Administration Review. No 66. PP. 437-447.

In citation: Belorusskiy Economicheskiy zhurnal. 2020. No 2. PP. 143-152.

Belarusian Economic Journal. 2020. No 2. PP. 143-152.

\title{
INCOME TAX PAYERS AS SIGNIFICANT PARTICIPANTS OF PROACTIVE BUDGETING
}

\author{
Elena Vylkova ${ }^{1}$, Anna Shmatko ${ }^{1}$ \\ Authors affiliation: ${ }^{1}$ North-West Institute of Management of the Russian Academy of National Economy \\ and Public Administration (St. Petersburg, Russia). \\ Corresponding author: Elena Vylkova (vylkova-es@ranepa.ru).
}

ABSTRACT. The article analyzes the state of proactive budgeting in the world and in Russia as well as identifies the main possible directions for its development. The directions of reforming the taxation of personal income in foreign countries and Russia over the recent years are considered. Demand for a fair and effective approach to taxation is shown. The feasibility of developing proactive budgeting in the context of the personal income tax (PIT) reform in terms of expanding the rights of honored and distinguished taxpayers of PIT for participation in participatory budgeting is substantiated. Suggestions have been formulated to amend the regulatory framework on proactive budgeting, to encourage honored and distinguished taxpayers, and to provide them with the opportunity to actively participate in creating a list of projects as well as making decisions on their financing.

KEYWORDS: tax, taxation, personal income tax, proactive budgeting, fairness, integrity.

JEL-code: G38, H10; H21.

DOI: $10.46782 / 1818-4510-2020-2-143-152$ 